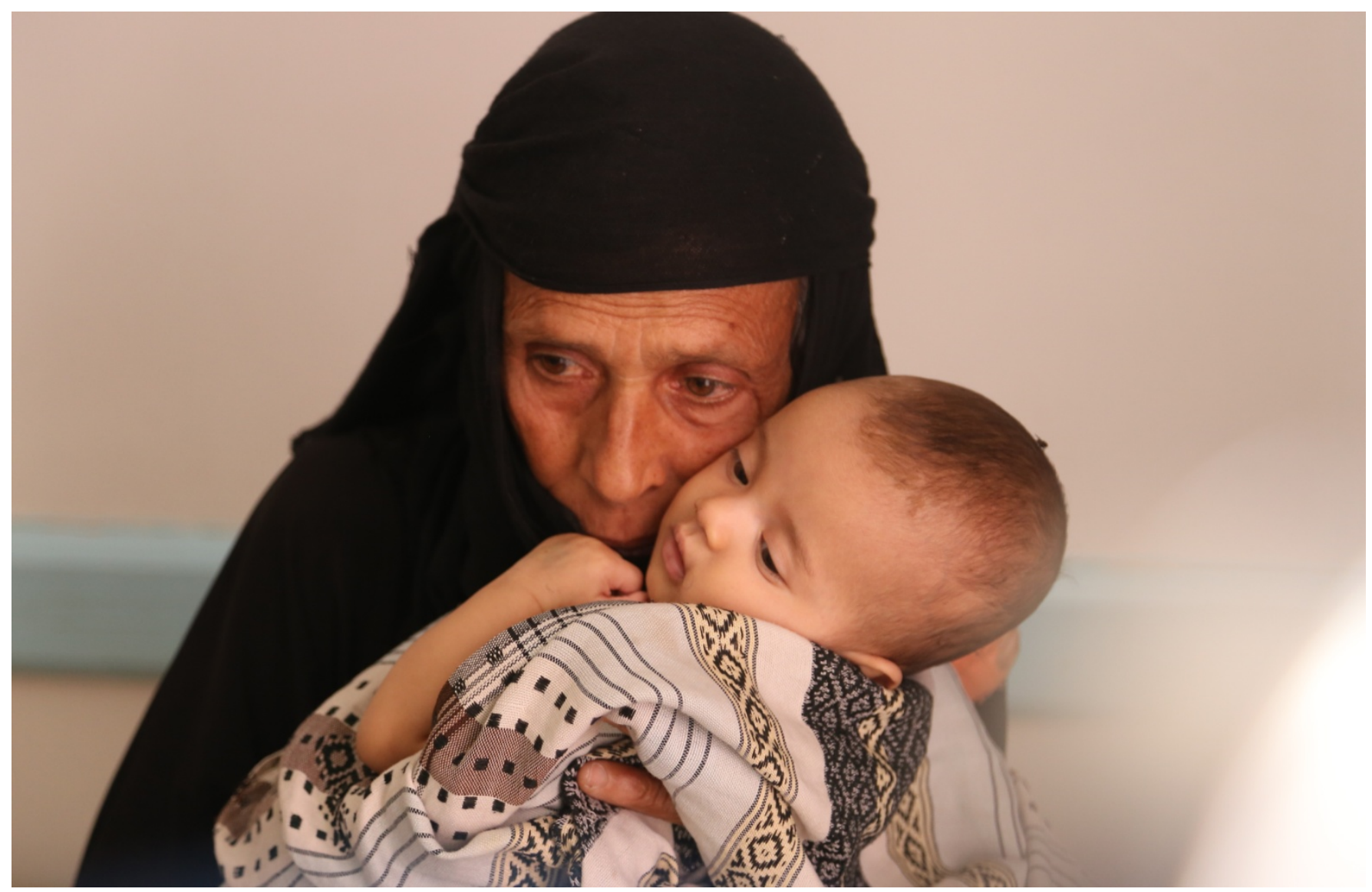

Hayat, five months old, from Haradh District, Hajjah governorate. Photo: Ameen Al-Ghaberi

\title{
YEMEN: \\ CATASTROPHIC \\ CHOLERA CRISIS
}


Since the end of April 2017, Yemen has been experiencing its worst recorded outbreak of suspected cholera in a single year. By mid-August, more than 500,000 cases were recorded. More than two years of war have devastated large parts of Yemen's infrastructure and left the majority of the population lacking basic services such as clean water or enough to eat. Levels of food insecurity and malnutrition are high, and make people even more vulnerable and susceptible to disease. Governorates with high levels of food insecurity are among those worst affected by cholera. Salaries in the public sector have not been paid for nearly a year, which means that people have less access to what is left of the health sector.

The current rainy season is likely to aggravate the spread of cholera and other diseases can easily break out, as a recent increase in meningitis cases shows. And all efforts to contain the multitude of crises have failed so far. Hence, all efforts need to focus on an integrated response, taking into account the links between food insecurity, disease and the need for livelihoods in order to build people's resilience to further shocks.

Significant and urgent scale up in all areas of intervention is needed, and institutional infrastructure needs to be maintained to ensure at least basic service deliveries. But ultimately, Yemen's crises can only be addressed effectively in an environment of peace, not war. 


\section{CONFLICT: BREEDING GROUND OF HUNGER AND DISEASE}

Since late April 2017, acute watery diarrhoea (AWD) and cholera have spread across the whole of Yemen, with a particularly rapid daily increase of infection throughout June and early July. From 27 April to 14 August, 503,484 AWD/ suspected cholera cases and 1,975 associated deaths have been reported. ${ }^{1}$ Twenty-one of Yemen's 22 governorates ${ }^{2}$ are affected, with the highest numbers in Amanat al-Asima (Sana'a city), Hodeidah, Hajjah, Amran and Ibb, where more than half of all reported cases since April have been registered. Although the rate of infection started to decline by mid-July, numbers could rise quickly again with the onset of the second part of the rainy season in August and September. Yet, while the AWD/cholera outbreak might be the most reported issue that Yemenis have to grapple with at the moment, it is by no means an isolated crisis. Several factors, resulting directly from the effects of the war, have constituted drivers for the cholera outbreak or barriers to fighting the disease effectively.

After more than two years of war, large parts of the country's infrastructure have been destroyed, the public service sector is close to collapse, and 60 percent of the population does not have enough to eat. ${ }^{3}$ Prolonged periods of food insecurity and malnutrition have made people vulnerable to disease, especially the elderly, children, and pregnant and lactating women. The governorates of Hajjah and Hodeidah, for example, are in phase 4 of the integrated food security phase classification (IPC) that measures levels of food insecurity in countries in crisis. Phase 4 governorates show extremely high levels of food insecurity, classified as an emergency. ${ }^{4}$ Hajjah and Hodeidah are also among the three governorates with the highest numbers of suspected cholera cases. ${ }^{5}$

With the partial destruction of the country's infrastructure and a payment crisis in the public sector, public services have largely collapsed. Water supply is intermittent, waste remains uncollected in the streets and damaged sewers leak, providing an environment for diseases like cholera to spread easily. The breakdown of service delivery in many areas also hampers the cholera response. Less than half of Yemen's health facilities are fully operational. ${ }^{6}$ With the loss of livelihoods and the absence of salaries, many people cannot even afford transport to cholera treatment centres (CTCs). Humanitarian organizations find it difficult to reach people on the ground due to restrictions on movement and lack of supplies, as well as lacking the resources to meet the level of need. 


\section{OXFAM'S CHOLERA RESPONSE}

Oxfam has been implementing cholera prevention activities and scaling up water, sanitation and hygiene (WASH) activities across the country, targeting internally displaced people (IDPs) and host communities living in camps, urban and rural areas. More than 400,000 people in seven governorates have been reached since early May. Oxfam has focused on engaging communities and training community health volunteers (CHVs) in understanding the risks of cholera (causes, symptoms, and preventative methods). Response planning and action sessions are held with community representatives such as teachers and imams. Support also includes assistance to health, water and solid waste management authorities through the provision of fuel, spare parts, generators, pumps and incentives (e.g. payment of stipends), as well as the provision of water and sanitation facilities at cholera treatment centres, the distribution of aquatabs (water purfication tablets), water containers, oral rehydration salts, and the disinfection of key water sources in communities.
'Now most of our burdens are relieved because Oxfam provided us with latrines and water!'

Abdulfatah Ghaleb, 37, father of seven living in an IDP camp in Alhawban district, Taiz governorate.

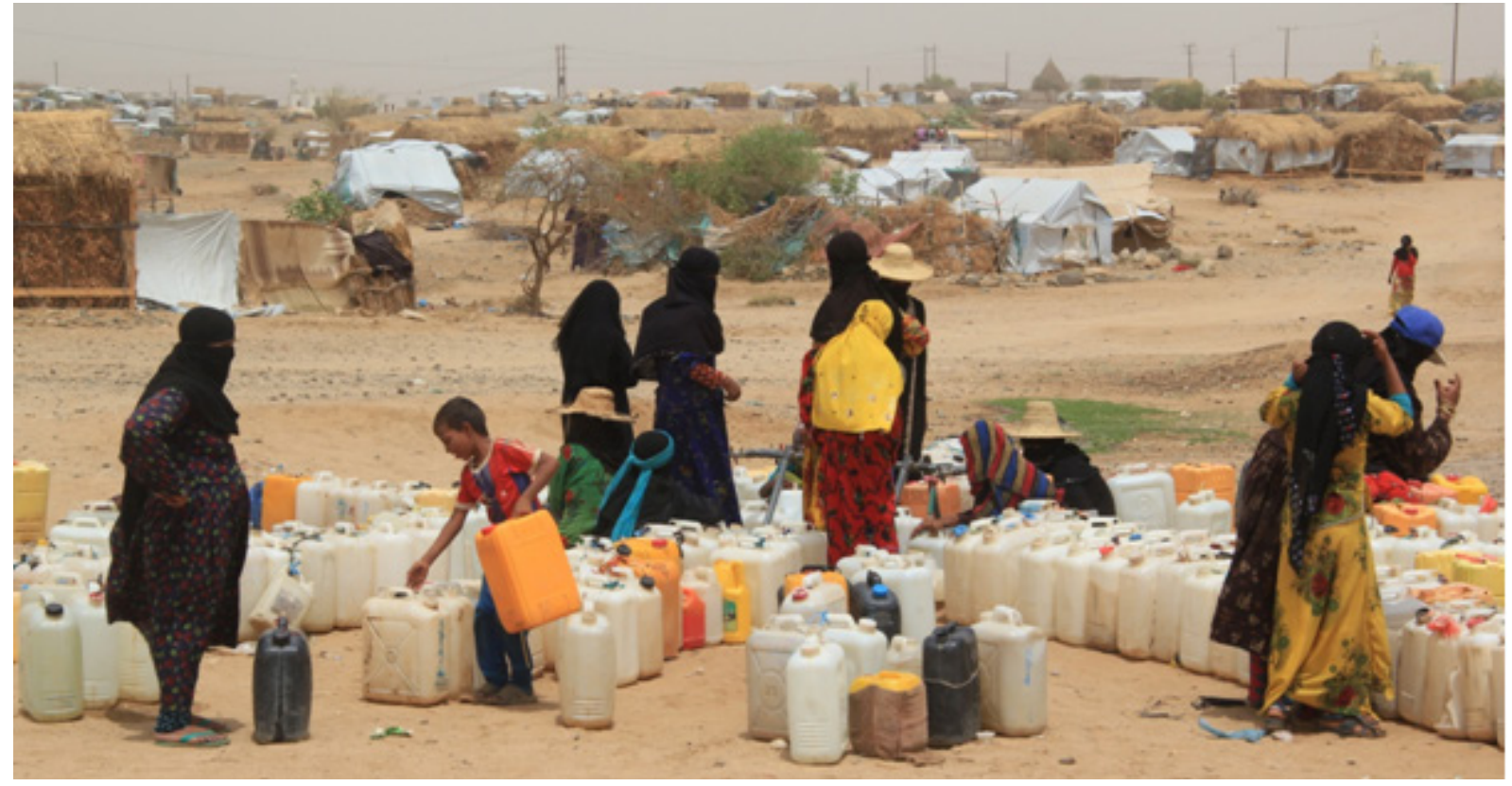

Water point in Al-Manjorah Camp, Bani Hassan, Abs district, Hajjah governorate. Photo: Ahmed Alfadheel.

However, the cholera response is impeded by a constant shortage of supplies. It is difficult to replenish them as Sana'a airport is closed for commercial flights, with no alternatives. With the help of the World Food Programme (WFP), Oxfam has flown in 39 tons of water tanks, chlorination kits, pipes, tap stands, buckets, and water testing kits, to be distributed to its four programme offices in Hajjah, Amran, Aden and Taiz. An additional 13 tons of supplies flown in from Pakistan and South Africa still sits in Djibouti at the time of writing (14 August 2017). Yet, as other aid agencies are also trying to bring in supplies, cargo space is scarce and transportation takes time. In addition, convoys need to be de-conflicted, i.e. cleared by the Saudi-led coalition in order not to be mistaken for a target by an airstrike. While the supplies in country have reached Oxfam offices in Hajjah and Amran, deliveries to Taiz and Aden are still facing bureaucratic hurdles that are delaying a rapid response.
'I know about cholera and how to prevent it as such but when my husband fell sick, I didn't know how to stay safe with my baby while taking care of him. The CHVs were following up with me and discussed the relevant measures. This helped me not getting infected as well.'

Sameera, a pregnant woman from Hajjah. 


\section{3 CHALLENGES TO AN EFFECTIVE CHOLERA RESPONSE}

Despite the efforts of the humanitarian community, a number of factors severely challenge an effective and rapid response to the cholera outbreak - and even provide favourable conditions for the disease to spread.

\section{NO MONEY, NO SERVICES}

After more than two years of war, which has resulted in a collapsed economy, around three million IDPs, and public sector workers without regular salaries, millions of people have run out of cash to pay for their most basic needs. Many others who are not public sector workers are also barely able to afford the costs of transportation, medicine and doctor's fees, often at the expense of having food on the table. They have to rely on selling their personal belongings and going into debt. Hence, seeking medical treatment is often the last resort, and many only do so when it is already too late. IDPs who have lost their livelihoods are the most vulnerable. Mohammad Ahmed, a 33-year-old farmer from Sa'dah, says he has to take his mother to hospital every three months as she suffers from a heart condition. He had to sell his wife's jewellery and his Jambia (a popular Yemeni dagger and belt), and fellow IDPs gave him some money out of sympathy. Ahmed says, 'I have no more money for my mother's next visit, and I don't know where I am going to get it from, I have sold everything I own.'

\section{Box 1: Challenges reaching medical care}

In the mountainous area in the north of Yemen, people have to travel far to reach the nearest health facility. In the districts of Aslam and Khairan in Hajjah governorate, among those worst affected by the cholera outbreak, transportation to the nearest hospital can easily cost 15,000 Yemeni riyals - the equivalent of about $£ 45$ (US $\$ 60$ ) $-\mathrm{a}$ fortune for families living in these areas.

Yet, this is also true for other parts of Yemen. Abdo, 40, lives in a remote area in Dhamar governorate, south of Sana'a with no cars available. His friends had to carry him on their shoulders four kilometres uphill, until they found a car to drive them to the nearest health centre five kilometres away. Abdo recalls 14 people from his village who were also infected, including two women who died. They all had to travel the same distance.

Approximately 1.2 million civil servants - more than one-third of all public sector workers - have not or only partially received their salaries since August 2016. Around seven million Yemenis depend on these public wages, based on the average size of a Yemeni family. ${ }^{7}$ Having no money has dramatically reduced the accessibility of food in the market for those people. But beyond the financial difficulties for the individual, the payment crisis has also affected essential parts of the institutional infrastructure that are crucial to an effective cholera response. Solid and liquid waste remains uncollected in the cities, providing a potential breeding ground for diseases like cholera. Up to 30,000 health workers have not been paid or paid only partially; they are key to an effective cholera response that connects with communities to ensure they understand the risks of cholera and

\section{'I have no more money for my mother's next visit, and I don't know where I am going to get it, I have sold everything I own.' Mohammad Ahmed}


how to mitigate them. ${ }^{8}$

The devastating impact of the war is particularly apparent in the health sector. Seventeen percent of the country's health facilities are non-functional and 38 percent only partly functional. ${ }^{9}$ Primary healthcare is now almost entirely dependent on foreign aid, except for the irregular payment of meagre salaries to the remaining medical personnel. ${ }^{10}$ Less than a third of Yemenis have access to medical care, and according to UNICEF, one child dies every ten minutes in Yemen because of preventable diseases such as diarrhoea, malnutrition and respiratory tract infections. ${ }^{11}$ There has been a 76 percent increase in the number of people requiring access to healthcare since late 2014, illustrating the magnitude of the health system's collapse after over two years of conflict, a system that had been already weak. ${ }^{12}$ The number of people lacking healthcare increased from 8.8 million before the escalation of the conflict in March 2015 to 14.8 million in April 2017. ${ }^{13}$ Less than 30 percent of the needed medicines and medical supplies are entering Yemen, where almost 100 percent of medication was imported prior to the conflict. ${ }^{14}$ Thus, health facilities lack essential supplies such as oxygen and fuel for generators, and medical staff of whom many either left the country or were forced to flee their homes. ${ }^{15}$ Without essential supplies, the functioning of emergency units, dialysis centres, operation theatres, and incubators has been severely curtailed. ${ }^{16}$

As a result, the remaining hospitals and health units are overwhelmed. The situation was already critical but with the new cholera outbreak, health facilities are unable to absorb the number of patients seeking treatment each day. One hospital in Sana'a reported that they receive as many as 300 AWD/cholera cases a day, while experiencing a shortage of intravenous fluids. This daily estimate of cases is not unusual. A cholera treatment centre in Abs in Hajjah governorate reported that at multiple points throughout the last three months, the centre has been receiving as many as 200 cases a day. Reports like this are repeated throughout the country, with patients even lying in the parking space outside of hospitals because there is no room left inside. However, treating cholera is technically a basic medical intervention, and even non-functioning and partly functioning health facilities can be easily revived with the correct and appropriate interventions to serve the population.

There is a shortage of Oral Rehydration Centres (ORC), as only 60 percent of the 2000 ORCs required are established across the 21 of the 22 governorates affected by the disease. The deaths in rural areas will be most likely severely under-reported. Access to care is further compromised by active frontlines, checkpoints and, in some areas, mines. Fear of being caught in crossfire or even of being directly targeted prevent many in active conflict zones from reaching a hospital, even if they are severely ill. ${ }^{17}$

'The elderly are unaware of the symptoms. They are seeking medical attention far too late, sometimes too late to be saved. Cholera can take hold within two hours. Rural communities need the most support. They do not have the money or fuel for transportation to seek treatment. But where should they go?' Doctor in one of Sana'a's main hospitals 


\section{Where does the cholera come from?}

Box 2: Cholera is an acute diarrhoea infection caused by ingestion of food or water contaminated with the bacterium Vibrio cholerae.

AWD/Cholera: Acute Watery Diarrhoea (AWD) - is a symptom of cholera and other diseases. It is characterized by three or more loose or watery stools within a 24-hour period and lasts for several hours or days.

Symptoms: The first symptoms of cholera are usually acute profuse watery diarrhoea, often with severe vomiting. The loss of electrolytes leads to dehydration, with signs of severe dehydration, leading to death if left untreated. Cholera can kill within hours if untreated.

Transmission: Cholera transmission is usually faecal-oral. A person can become infected by drinking water or eating food contaminated with the bacterium Vibrio cholerae.

Prevention: Methods of preventing cholera include ensuring access to adequate safe water, safe food, good hygiene, safe excreta disposal, hand washing with soap, environmental hygiene in markets and public places, surveillance and early warning to detect cases and early access to case management.

Treatment: Cholera is treatable. Up to 80 percent of people can be treated successfully through prompt administration of oral rehydration solution (ORS) along with zinc. ORS is clean water with a mixture of salt, sugar and electrolytes.

Despite efforts, the source of the current AWD/cholera outbreak has not yet been identified. Cholera is a waterborne disease. Although not proven, it is very likely that contaminated water sources are among the main sources of the epidemic. Two-thirds of the Yemeni population do not have access to clean water. Historically a very water-scarce country, Yemen's public water and sanitation systems are on the verge of collapse as a result of the war. Water facilities have been repeatedly hit and the water infrastructure has been damaged by parties to the conflict. IDPs are struggling to find potable water, sanitation and hygiene services. Across the country, water networks in rural and urban areas have reduced services or have stopped functioning altogether, and local water corporations in most governorates are no longer able to maintain or rehabilitate the infrastructure. Water trucking becomes too expensive for many, as the rising price of fuel needed for pumps and transportation is also increasing the price of water. More and more people are resorting to untreated water sources or unprotected wells.

In Amran, people in districts along the valley Wadi Uthman use the open water running through the valley to collect water for cooking, to bathe, to wash clothes, and to water animals. Figures of AWD/suspected cholera are particularly high in these districts. Given the nature of the transmission of cholera, it is most likely that contaminated drinking water is the main source. In rural communities, access to sanitation facilities such as latrines is often limited. Hence, it can spread rapidly in areas with inadequate containment of human faecal waste, unsafe and open water sources, and poor levels of hygiene. ${ }^{18}$ 


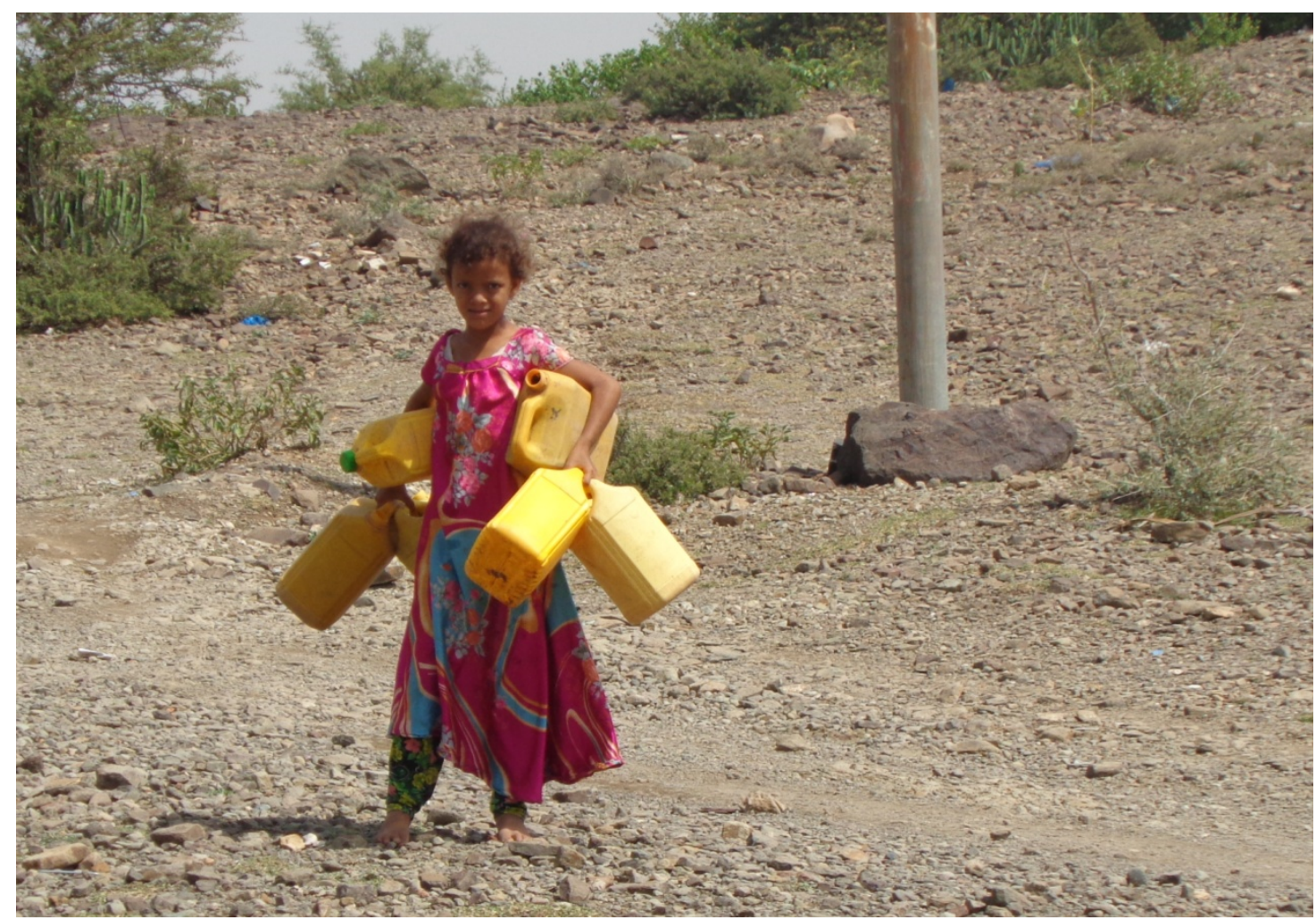

Hurriya, 9, gets drinking water from a dirty uncovered water source in Altaiziah district, Taiz governorate. Photo: Zeyad Ghanem.

Historically in Yemen, diarrhoeal diseases (such as cholera) are endemic and typically increase during the summer season. Part of the difficulty in getting an understanding of the epidemic and accurate figures is the lack of laboratory testing facilities to confirm cholera cases, as opposed to other forms of AWD. As of 19 July, only 659 lab-confirmed cholera cases were registered out of more than 350,000 . $^{19}$ The only laboratories - in Sana'a, Aden and Hodeidah - are not adequate to respond to the need of testing appropriate numbers of suspected cases from the entire country. Although rapid tests are available in some hospitals, they can only confirm negative cases. Their false rate in positive cases is very high, i.e. some cholera cases tested positive are in fact not cholera. ${ }^{20}$ Issues in information management between reporting and recording, and the technical capacity in line-listing the number and diversity of cases of AWD/cholera further complicate getting accurate statistics on the number of AWD cases as opposed to confirmed cholera cases - information that could help to gain a clearer picture on whether there are areas with particularly high numbers of cholera as opposed to AWD cases. 


\section{NOT ENOUGH TO EAT}

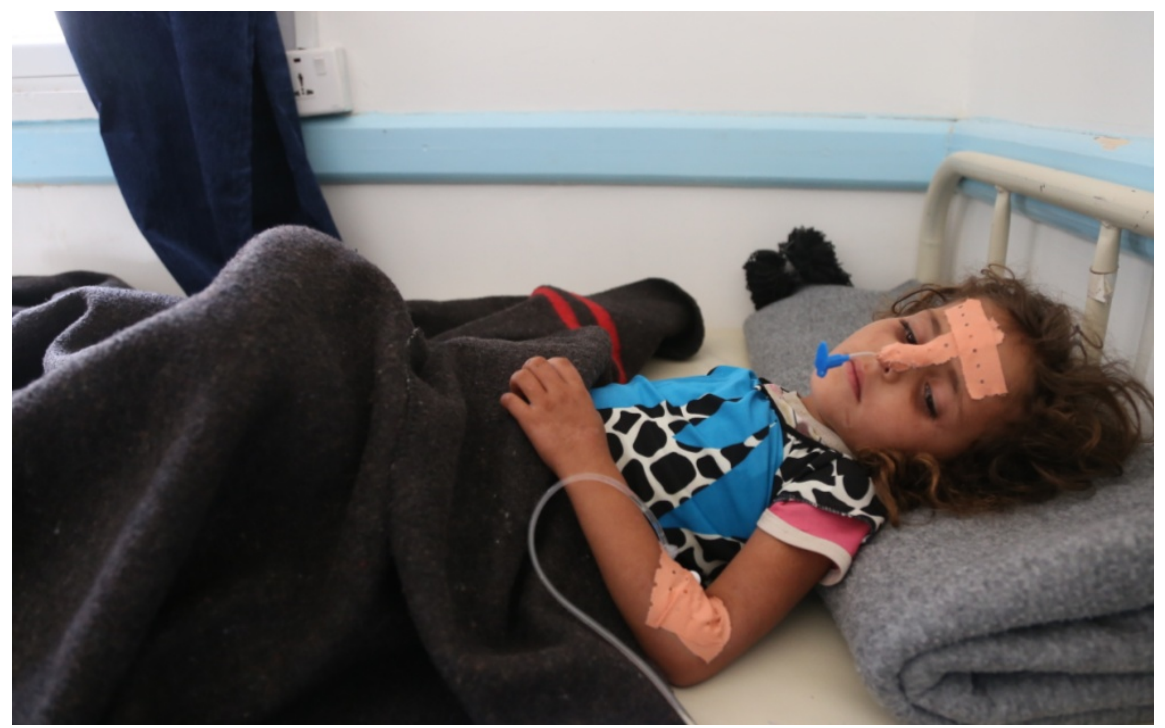

Hind suffers from both cholera and malnutrition. She is being fed through a nasal tube- Al-Sabeen Hospital, Sana'a. Photo: Ameen AlGhaberi

Due to the effects of malnutrition, Yemen's population has been particularly vulnerable to the spread of diseases like cholera. A convergence of cholera and food and nutrition needs has been observed in 67 districts in Yemen. ${ }^{21}$ As shown in Figure 1, districts where high levels of food insecurity and high numbers of AWD/cholera cases overlap are found throughout the country, including coastal, central and mountainous regions. Areas such as the north of Sa'dah, parts of Hajjah and Amran, and Lahj and Abyan are among those the hardest to reach, as active frontlines and instability hamper humanitarian interventions.

Figure 1: Convergence of food insecurity and cholera in Yemen

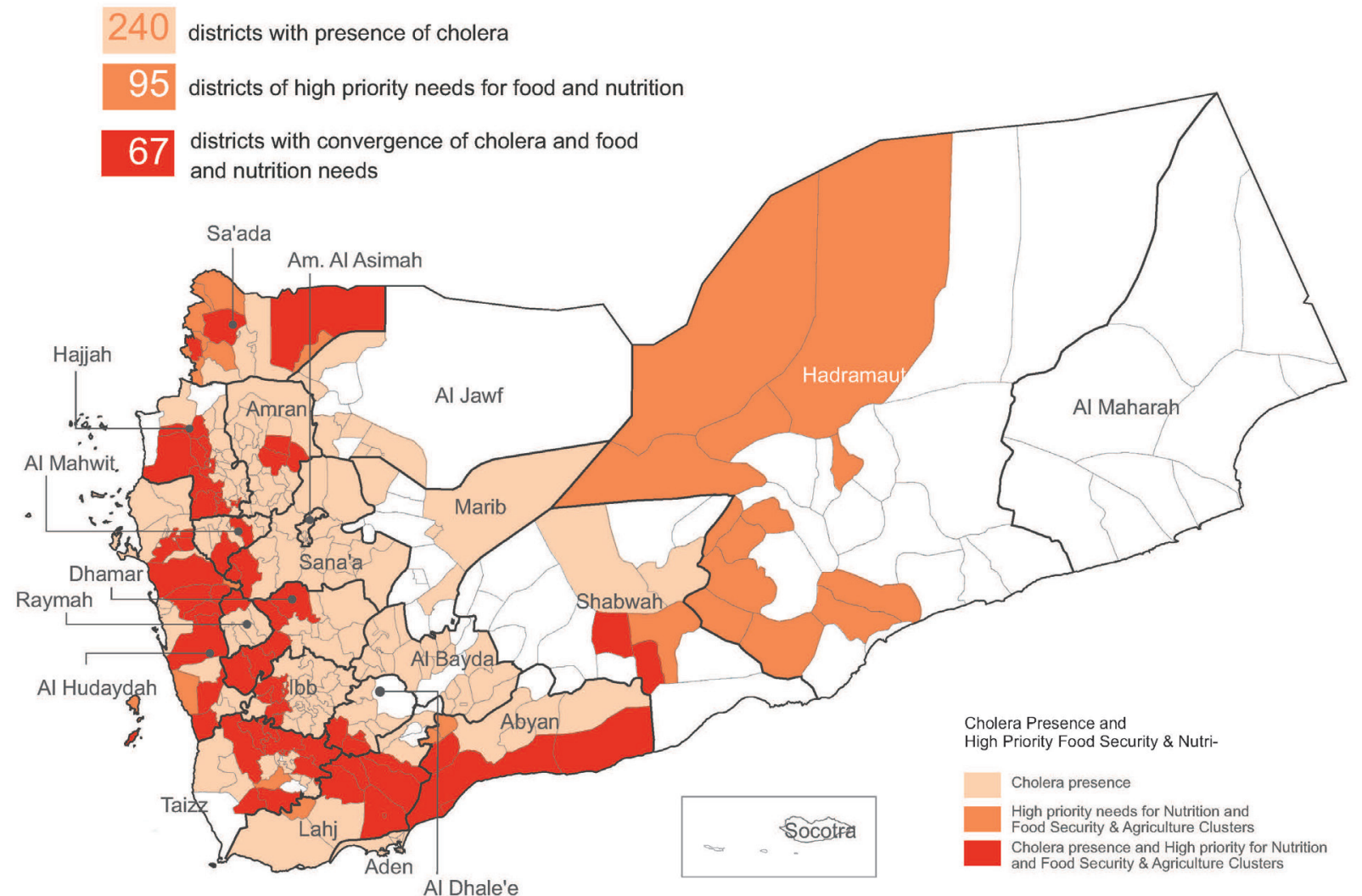

Sixty-seven districts show the convergence of high levels of food insecurity and high numbers of cholera. Source: Yemen Periodic Monitoring Review Jan-April 2017. 
Yemen was already the poorest country in the Arab world when the war began in March 2015, with a national global acute malnutrition (GAM) rate of 12.7 percent as of August $2014 .^{22}$ GAM rates indicate the nutritional status of a population and are used to determine the severity of a humanitarian crisis. In March 2017, GAM rates above the global emergency threshold of 15 percent according to WHO standards were assessed in four governorates (Taiz, Abyan, al-Hodeidah and Hadramout). Even more worrying, severe acute malnutrition (SAM) rates have peaked. ${ }^{23}$ By the end of 2016 , the SAM rate among children had increased by a staggering 200 percent. ${ }^{24}$ The effects of the war, in particular the imposition of road taxes, have led to an increase in food prices of up to 22 percent. At the same time, the population has less and less access to cash and paid work. As a result, 17 million people in Yemen are food insecure (60 percent of the population), with 6.8 million people on the brink of famine. With people's resilience decreasing, their ability to fight disease and recover has diminished. The rate and severity of malnutrition is likely to rise further as many who had contracted AWD/cholera and recovered, especially children, are left physically weakened and vulnerable.

\section{CULTURAL BARRIERS}

Women are often among the most vulnerable in humanitarian crises. They look after the sick at home, eat less in order to feed their children, and are often the last to receive medical treatment. In Yemen, they face the additional burden of not always being allowed to go to a cholera treatment centre (CTC) on their own. Hospital staff told Oxfam that in more conservative parts of the country, they have received cases where relatives refused to leave a female patient alone at the CTC and rather took them back home. Due to the limited capacity of hospitals, only one caregiver is allowed to stay with a patient. If family members insist on more than one person staying with a female patient, they are all not allowed to enter the hospital. As it is regarded as shameful for women and girls to admit that they are suffering from diarrhoea, adequate treatment for them is often delayed. Thus, women are at particular risk of not receiving rapid and adequate treatment.

\section{Box 3: Women at risk}

In a conservative society such as Yemen, women face particular difficulties in situations of conflict. Especially in IDP camps where three households have to share a latrine, men have to escort female family members every time they visit the latrines. This is a particular problem in cases where latrines are shared by nonrelatives. When he was told that latrines prevent the spread of diseases, Muthana, an IDP from Sa'dah, living in a refugee camp, replies, 'I would rather dig a one meter hole for my wife to defecate than send her with a stranger. We are conservative people and it's shameful for us to send our women with strangers. We would rather die than witness that, and we will never accept it no matter what.'

Local perceptions and fear around one's reputation are not limited to women, but are hampering the fight against cholera in all areas of society. Oxfam has observed a fear of social stigma in reporting to a health centre with AWD/cholera symptoms. In rural areas, people are afraid that their neighbours could see them at a diarrhoea treatment centre (DTC) and subsequently shun them out of fear of contracting the disease. In urban areas, people are reluctant to tell their employers if they suffer from suspected cholera as they fear rejection by colleagues and long periods off work that could jeopardize their employment status. In rural communities, people would also consult traditional doctors before 
reporting to a hospital. Thus, in some cases, people in a severe condition report too late to a hospital when earlier treatment would have been easier and quicker. Time and resources are needed to engage with communities on these issues - to understand their perceptions, myths, and stigma around cholera and how to overcome these challenges and promote acceptance in cholera-affected people to seek help early on.

\section{ACCESS RESTRICTIONS FOR INGOS}

Despite the severity of the humanitarian situation, particularly with regard to the AWD/cholera epidemic, many humanitarian organizations report access restrictions in form of inland travel permits being withheld for national staff; ad hoc and notorious check points where vehicles are stopped and/or taken for days or weeks; car-jacking and long visa processes, despite the urgent need for cholera and other humanitarian response specialists.

Obtaining visas for INGOs' necessary international staff can take up to two months. But due to a lack of salaries, visa authorities, like other public institutions, lack the staff and money to operate at a normal speed. The high demand for new visas from INGOs is further slowing down the process. At the onset of the cholera crisis, INGOs were guaranteed to receive visas within two weeks for cholera specialists. Yet, INGOs experience severe delays with cholera specialists and other essential staff for an emergency response being stuck abroad for over a month. Once in Yemen, international aid workers have to wait another four days for a travel permit to be issued in order to reach the people in need. Travel permits also further restrict the flexibility to respond to immediate needs, which is already hampered by international staff not being able to cross the frontline.

The teams on the ground struggle with access challenges, as even national staff need travel permits to reach beneficiaries. While some local authorities are notorious for rejecting travel permits unless they are allowed to dictate the list of beneficiaries, staff that have travel permits often see those permits rejected at checkpoints or arbitrarily withdrawn. With restricted access to some communities desperately in need, not only is essential humanitarian aid not distributed, but important assessments cannot be carried out into which interventions against cholera have been effective and what level of knowledge on cholera prevention communities have.

Recently the UN and INGOs have been asked by the legitimate government of Yemen to ensure that visas are obtained through their diplomatic representative. So far, this has only been necessary for the southern part of the country, and visas for the north are granted in Sana'a. But from 16 August, new visa applications need to go through the dual process, which is likely to cause additional administrative burdens for INGOs.

Local conflicts and the militarization of certain parts of the country pose additional challenges. Harf Sufyan district, north of Amran governorate, has a big military camp that is often targeted by airstrikes. The estimated civilian population of 60,000 is reportedly facing one of the highest numbers of suspected cholera cases, but due to the militarization of the area, aid agencies cannot access the communities and thus have no confirmation of the actual situation.
'When we were chlorinating main water sources, we were stopped until a permit was issued. Yet, the permit was only issued three weeks later; else we could've saved more lives!'

Humanitarian staff 
None of the humanitarian response in Yemen - including the fight against cholera - is possible without adequate funding. However, humanitarian agencies have had to reallocate funds from food security programmes to the cholera response because the humanitarian response in Yemen has been underfunded. This is counter-productive in a context in which food insecurity is making people more vulnerable to diseases, and where cholera is likely to cause even higher rates of malnutrition. Hence, all efforts need to focus on an integrated response, taking into account the links between food insecurity, disease and the need for livelihoods in order to build people's resilience to further shocks. Therefore, the Yemen Humanitarian Response Plan (YHRP) needs complete funding more than ever. As of 14 August however, less than half of the US $\$ 2.3 \mathrm{bn}$ requested for the YHRP has been released. ${ }^{25}$

Despite the inter-agency response, the scale of AWD/cholera is beyond the capacity of agencies and humanitarian organizations. WASH activities are needed in 121 affected districts, and 164 affected districts need health interventions. ${ }^{26}$ Thus, in addition to the activities of the inter-agency Health and WASH clusters, significant and urgent scale up in all areas of intervention is needed. The Emergency Operation Centre (EOC) that is currently being set up is supposed to pool resources and coordinate the inter-agency cholera response on national, governorate and district levels together with the relevant ministries. However, establishing the EOC is taking more time than expected. While the central office in Sana'a has been set up, setting up offices at a governorate level has been slower.

Functioning service delivery is crucial in order to address the pressing underlying issues of the cholera outbreak in a comprehensive and sustainable manner. Institutional infrastructure needs to be maintained to ensure at least basic service delivery, e.g. through providing supplies for the cholera response and some form of remuneration in the absence of salaries. In particular, the ministries of water and solid waste management, and health play a crucial role. The Ministry of Planning and International Cooperation (MoPIC) is also imperative for facilitating INGOs' access to and within the country.

Ultimately however, the humanitarian crisis in Yemen, including the AWD/cholera outbreak, can only be addressed effectively in an environment of peace, not war. Efforts to support a viable and effective peace process with the meaningful participation of women and civil society groups must be stepped up. This should include international diplomatic, financial and technical support to ensure such groups have a place at the table and an influential voice in a reinvigorated peace process. Additionally, the conflict parties should demonstrate their respect for all Yemeni citizens by creating a meaningful space for such participation at all levels of the peace process. Yemen's long-term peace and stability depends on a political solution that responds to the needs of all Yemenis and enjoys widespread public support. All actors and the international community need to invest in a viable peace process to create an environment that is suitable for rebuilding the country's infrastructure, tackling root causes of conflict, and invest in the development of future generations. 


\section{RECOMMENDATIONS}

\section{National actors and government authorities:}

- All parties need to commit to an immediate ceasefire and cessation of hostilities, and prioritize inclusive political solutions to end the bloodshed and facilitate humanitarian assistance.

- The conflict parties need to create a meaningful space for the participation of women, civil society, youth and minority groups at all levels of the peace process.

- All parties to the conflict, as well as local power holders need to ensure unimpeded access to all people in need. This includes national as well as local authorities and administrations. All barriers to access for humanitarian personnel (national and international) to beneficiaries in the field need to be lifted. National staff should not be obliged to obtain inland travel permits as these are imposed solely on the basis of their INGO capacity. All sides of the conflict need to ensure the safety of humanitarian personnel and their equipment.

- Visa processes for humanitarian workers must be speeded up and a duplication of the process by Sana'a and Aden-based authorities and administrations should be streamlined.

- Movement for national and international humanitarian workers between Sana'a and Aden needs to be facilitated through regular UNHAS flights.

- Health officials need to establish a disease surveillance system and provide daily reports in order to monitor the spread of the outbreak.

\section{Donors and the international community:}

- Increase pressure on warring parties and their international allies to return to the negotiating table and set up a peace process. Priority must be given to an immediate and comprehensive ceasefire across the whole country.

- Efforts around the peace process need to include international diplomatic, financial and technical support to ensure all parts of the Yemeni society have a place at the table and an influential voice.

- The international community has to come to Yemen and engage with all actors on the ground in order to gain first hand understanding of the situation, build meaningful interventions and long term engagement, and facilitate the operational space for INGOs.

- Fully fund the YHRP 2017. Step up the Cholera Emergency Fund and provide sufficient funds for the food security crisis. Both crises need an integrated and coherent approach that provides enough funds for both responses.

- Funding must include allocations for supplies and logistics. Yemen needs to be prepared for another cholera outbreak and unexpected surges, and medical stocks need to be constantly supplied with IV fluids and ORS sachets. Resupply chains should be set up and be able to respond quickly.

- Access of humanitarian and commercial goods to and within the country must be ensured and all points of access need to be kept open and accessible. Funding and logistics such as cargo planes and storage capacities need to be provided in order to enable the shipment of sufficient quantities of humanitarian goods into Yemen.

- Use all available channels of communication with national actors to facilitate the transport of humanitarian goods within the country without delay, and 
ensure its safe and unhindered access to people in need.

- Press all sides with influence in Yemen and all parties to the conflict and states who support them to prioritize payment of salaries. Support these efforts with incentives such as supplies and stipends to allow the delivery of basic services. The country is being devastated by conflict, and the neglect of the public sector is greatly accelerating this.

- Make long-term and flexible funding available in order to support WASH infrastructure and livelihood interventions, and ensure adequate funding is available for development where the local landscape allows.

\section{For UN agencies, INGOs, and the international community:}

- The overall humanitarian crisis in Yemen and the cholera outbreak in particular, need a prompt, adequate and comprehensive response.

Coordination and collaboration on the cholera response within the framework of the EOC needs to be comprehensively implemented in order to ensure an all-encompassing response and be ready to respond to future health crises. Therefore, future contingency planning with a clear distribution of tasks needs to be implemented.

- Coordinate and streamline data collection. Improve information management around reporting and recording cases to get clearer and more precise figures. Implement a surveillance and early warning system to detect cases at the early start of an epidemic.

- All international actors need to engage in a meaningful way with communities on the ground. Action has to be taken to mobilize communities to reduce the risks of diseases. This needs long-term engagement instead of one-off distribution campaigns. 


\section{NOTES}

1 The WHO published updated figures on a daily basis under: http://www.emro.who.int/yem/yemeninfocus/situation-reports.html

2 The island of Socotra off the Horn of Africa has not been affected by the outbreak, possibly due to its remote location in the Gulf of Aden.

3 Periodic Monitoring Review, April 2017, p. 7. Out of these 17 million, about 10.2 million people are in IPC phase 3 (crisis), and 6.8 million people are in phase 4 (emergency), out of five phases (phase 5 being famine). The number of people in phases 3 and 4 has increased by 20 percent between June 2016 and March 2017. IPC Yemen (2017). Acute Food insecurity Analysis Communication Brief. March 2017. http://fscluster.org/yemen/document/ipc-yemen2017-acute-food-insecurity-0

4 IPC (2017). Republic of Yemen: Acute Food Insecurity Projected Situation Overview. http://www.ipcinfo.org/fileadmin/user_upload/ipcinfo/docs/IPC_Yemen_AcuteFI_Situation_March -July2017_ENversion.pdf

5 WHO (2017). Yemen cholera outbreak. Daily epidemiology update: 30 July. Op. cit. http://www.emro.who.int/images/stories/Yemen daily_epi update_20170730.pdf?ua=1

$617 \%$ are left non-functional, $28 \%$ partly functional and only $45 \%$ are still fully functional. WHO, Ministry of Public Health and Population (2016). Service Availability and Health Facilities Functionality in 16 Governorates. p. 5.

7 UNDP (2016). Yemen rapid assessment report for December 2016: Measuring the impact of the public sector wage suspension on basic service delivery in the healthcare and education sectors. p. 7.

8 WHO, 27 July 2017, https://twitter.com/WHOYemen/status/890624297454116864

9 WHO, Ministry of Public Health and Population (2016). Service Availability and Health Facilities Functionality in 16 Governorates. p. 5.

10 OCHA Yemen Humanitarian Bulletin Issue \#19 (December 2016).

11 UNICEF (12 December 2016).

12 Yemen 2017 Humanitarian Needs Overview (November 2016), p. 11; http://reliefweb.int/sites/reliefweb.int/files/resources/YEMEN\%202017\%20HNO_Final.pdf.

13 WHO Regional Health Update, September-October 2016; WHO Yemen conflict Donor Update, April 2017.

14 OCHA Yemen Humanitarian Bulletin Issue \#19 (December 2016).

15 MSF Taiz report (January 2017) p 26.

16 OCHA Yemen Humanitarian Bulletin Issue \#19 (December 2016).

17 MSF Taiz report (January 2017) p 13

18 WHO Media Backgrounder on AWD and Cholera, 11 July 2017.

19 WHO, Yemen cholera situation report no. 4, 19 July 2017, p. 1.

20 Interview with MSF staff in Hawban, Taiz, July 2017.

21 UN Periodic Monitoring Review, April 2017, p. 14.

22 OCHA August 2014

https://www.humanitarianresponse.info/sites/www.humanitarianresponse.info/files/Yemen\%20H umanitarian\%20Snapshot\%20\%28Malnutrition\%29\%20August $\% 202014$.pdf. OCHA August 2014 ,

23 IPC analysis March 2017.

24 UNICEF December 2016, http://reliefweb.int/report/yemen/malnutrition-amongst-childrenyemen-all-time-high-warns-unicef-enar

25 As of 14 August 2017, 39 percent. https://fts.unocha.org/countries/248/summary/2017

26 UN meeting, 9 July 2017. 
(C) Oxfam International August 2017

This paper was written by Larissa Alles with guidance from Dina El-Mamoun. Oxfam acknowledges the assistance of Saif Alhaddi and Ibrahim Alwazir in its production. It is part of a series of papers written to inform public debate on development and humanitarian policy issues.

For further information on the issues raised in this paper please email advocacy@oxfaminternational.org

This publication is copyright but the text may be used free of charge for the purposes of advocacy, campaigning, education, and research, provided that the source is acknowledged in full. The copyright holder requests that all such use be registered with them for impact assessment purposes. For copying in any other circumstances, or for reuse in other publications, or for translation or adaptation, permission must be secured and a fee may be charged. Email policyandpractice@oxfam.org.uk.

The information in this publication is correct at the time of going to press.

Published by Oxfam GB for Oxfam International under ISBN 978-1-78748-036-0 in August 2017.

DOI: $10.21201 / 2017.0360$

Oxfam GB, Oxfam House, John Smith Drive, Cowley, Oxford, OX4 2JY, UK.

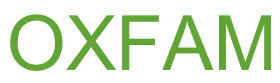

Oxfam is an international confederation of 20 organizations networked together in more than 90 countries, as part of a global movement for change, to build a future free from the injustice of poverty. Please write to any of the agencies for further information, or visit www.oxfam.org

Oxfam America (www.oxfamamerica.org) Oxfam Australia (www.oxfam.org.au) Oxfam-in-Belgium (www.oxfamsol.be) Oxfam Brasil (www.oxfam.org.br)

Oxfam Canada (www.oxfam.ca)

Oxfam France (www.oxfamfrance.org)

Oxfam Germany (www.oxfam.de)

Oxfam GB (www.oxfam.org.uk)

Oxfam Hong Kong (www.oxfam.org.hk)

Oxfam IBIS (Denmark) (www.ibis-global.org)
Oxfam India (www.oxfamindia.org)

Oxfam Intermón (Spain) (www.oxfamintermon.org)

Oxfam Ireland (www.oxfamireland.org)

Oxfam Italy (www.oxfamitalia.org)

Oxfam Japan (www.oxfam.jp)

Oxfam Mexico (www.oxfammexico.org)

Oxfam New Zealand (www.oxfam.org.nz)

Oxfam Novib (Netherlands) (www.oxfamnovib.nl)

Oxfam Québec (www.oxfam.qc.ca)

Oxfam South Africa (www.oxfam.org.za) 